\title{
Hepatitis E virus in liver and bile samples from slaughtered pigs of Brazil
}

\author{
Noemi Rovaris Gardinali $/{ }^{+}$, Aline Fernandes Barry, Rodrigo Alejandro Arellano Otonel, \\ Alice Fernandes Alfieri, Amauri Alcindo Alfieri
}

Departamento de Medicina Veterinária Preventiva, Laboratório de Virologia Animal, Universidade Estadual de Londrina, Londrina, PR, Brasil

The objective of this study was to detect and identify hepatitis E virus (HEV) strains in liver and bile samples from slaughtered pigs in the state of Paraná, Brazil. Liver and bile samples were collected from 118 asymptomatic adult pigs at a slaughterhouse in a major Brazilian pork production area. The samples were assayed using a nested reverse transcription-polymerase chain reaction protocol with primer sets targeting open reading frames (ORF)1 and 2 of the HEV genome. HEV RNA was detected in two (1.7\%) liver samples and one $(0.84 \%)$ bile sample using both primers sets. The HEV strains were classified as genotype $3 b$ on the basis of their nucleotide sequences. These data suggest that healthy pigs may be a source of HEV infection for consumers of pig liver and slaughterhouse workers in Brazil.

Key words: hepatitis E virus - swine - slaughterhouse

Hepatitis E, which is caused by infection with the hepatitis E virus (HEV), is a major public health concern in developing and industrialised countries. This member of the Hepevirus genus, which belongs to the Hepeviridae family, is a non-enveloped, single-stranded, positivesense RNA virus with a $7.2 \mathrm{~kb}$ genome that consists of three discontinuous open reading frames (ORFs) (Emerson \& Purcell 2006). The mammalian HEV is classified into four genotypes and one serotype; recently, novel unclassified strains were described in rabbits and rats $(\mathrm{Lu}$ et al. 2006, Zhao et al. 2009, Johne et al. 2010).

In developing countries, HEV outbreaks are mainly caused by infection with genotypes 1 and 2 . Hepatitis E is recognised as a zoonotic disease with sporadic cases in industrialised countries, caused by genotypes 3 and 4, for which pigs are the main reservoirs (Meng 2010). Autochthonous hepatitis $\mathrm{E}$ in non-endemic countries is often confused with drug-induced liver injury (Dalton et al. 2007). In the general population, the disease is often asymptomatic, although people with underlying chronic liver disease are at risk of developing and dying from fulminant hepatic failure in approximately $70 \%$ of infection cases (Dalton et al. 2008).

Occupational exposure to pigs by farmers, veterinarians, butchers and slaughterhouse workers has been linked to an increased risk of HEV infection (Galiana et al. 2008). The potential for domestic and wild swine to act as vehicles for HEV transmission has been linked to the consumption of raw or undercooked meat or viscera $(\mathrm{Li}$ et al. 2005, Colson et al. 2010). Other routes of zoonotic infection, such as direct exposure to pigs and pig faeces or environmental contamination, should not be excluded.

Financial support: CNPq, CAPES, FINEP, Fundação Araucária AFA and AAA are recipients of CNPq fellowships.

+ Corresponding author: no_rovaris@yahoo.com.br

Received 17 January 2012

Accepted 29 June 2012
In Brazil, the incidence of HEV infection in humans has been of minor concern. Previous reports showed that the overall HEV seroprevalence in the healthy population is approximately 4\% (de Paula et al. 2001). In pigs, genotype 3 of HEV has been reported from pig farms and slaughterhouses in several regions of Brazil [the states of Mato Grosso, São Paulo (SP), Rio de Janeiro (RJ) and Pará (PA)] (Paiva et al. 2007, dos Santos et al. 2009, 2011, de Souza et al. 2012).

Brazil is one of the most important pork producers and exporters in the world. The South Region, including the states of Paraná (PR), Santa Catarina and Rio Grande do $\mathrm{Sul}$, is one of the largest pig-producing regions in the country. The objective of this study was to evaluate the presence of HEV in porcine liver and bile samples at a slaughterhouse in PR and to perform a phylogenetic analysis of swine and human HEV strains circulating in Brazil for a comparison with strains circulating in other countries.

Liver and bile samples were collected from 118 adult pigs at one slaughterhouse in PR, which is under the control of the Federal Inspection Service. The samples were obtained in July of 2010 and were drawn from healthy animals with an estimated age of 25 weeks or older that were farmed in 10 different herds in the western region of PR. A total of 10-15 samples from each herd were obtained. Each bile sample was withdrawn with a sterile disposable syringe using a needle puncture through the gallbladder and one part of the inner liver was excised using a new sterile scalpel blade for each specimen. The samples were stored at $-20^{\circ} \mathrm{C}$ until the analysis. Bile samples were suspended in $10 \%(\mathrm{w} / \mathrm{v})$ diethyl pyrocarbonate-treated water (Invitrogen ${ }^{\mathrm{TM}}$ Life Technology, Carlsbad, CA, USA). Liver tissue was disrupted manually and subsequently homogenised in $10 \%$ (w/v) phosphate-buffered saline $(\mathrm{pH} 7.2)$ and clarified by centrifugation for $10 \mathrm{~min}$ at $3,000 \mathrm{~g}$.

Viral RNA was extracted from $400 \mu \mathrm{L}$ aliquots of the liver and bile suspensions using a combination of phenol/chloroform/isoamyl alcohol and silica/guanidine isothiocyanate methods (Alfieri et al. 2006). Both the 
liver and bile samples were assayed using nested reverse transcription-polymerase chain reaction nested (RTPCR) with primers targeting ORF2 and the methyltransferase region of ORF1 of the HEV genome as previously described (Wang et al. 1999, Huang et al. 2002).

RT reactions were performed using $5 \mu \mathrm{L}$ of the extracted RNA; the reverse primer set was used at a concentration of $20 \mu \mathrm{M}(3517 \mathrm{~N} / \mathrm{ConsORF1-a1)}$ and ultrapure sterile water was added to a final volume of $10 \mu \mathrm{L}$. The initial denaturation step was performed at $97^{\circ} \mathrm{C}$ for 5 min. The samples were then placed on ice for $5 \mathrm{~min}$ and $10 \mu \mathrm{L}$ of RT mix containing 1x RT buffer (50 mM Tris$\left.\mathrm{HCl} \mathrm{pH} \mathrm{8.3;} 3 \mathrm{mM} \mathrm{MgCl}_{2} ; 75 \mathrm{mM} \mathrm{KCl}\right), 0.1 \mathrm{mM}$ of each dNTP (Invitrogen Life Technology, Carlsbad, CA, USA), $10 \mathrm{mM}$ DTT, 100 units of M-MLV reverse transcriptase (Invitrogen Life Technology, Carlsbad, CA, USA) and ultrapure sterile water were added to a final volume of 20 $\mu \mathrm{L}$. The solution was incubated at $42^{\circ} \mathrm{C}$ for $30 \mathrm{~min}$ followed by enzyme inactivation at $94^{\circ} \mathrm{C}$ for $5 \mathrm{~min}$.

The first round of PCR was performed using $8 \mu \mathrm{L}$ of cDNA added to $42 \mu \mathrm{L}$ of PCR mix containing 1.5x PCR buffer ( $30 \mathrm{mM}$ Tris- $\mathrm{HCl} \mathrm{pH} \mathrm{8.4;75} \mathrm{mM} \mathrm{KCl),} 2 \mathrm{mM}$ $\mathrm{MgCl}_{2}, 0.2 \mathrm{mM}$ of each primer (3156N-3157N/ORF2 and ConsORF1-s1-ConsORF1-a1/ORF1), 2.5 units of Platinum Taq DNA polymerase (Invitrogen ${ }^{\mathrm{TM}}$ Life Technology, SP, BR) and ultrapure sterile water to a final volume of $50 \mu \mathrm{L}$. The amplification was performed with the following cycling profile: an initial denaturation step of $2 \mathrm{~min}$ at $94^{\circ} \mathrm{C}$ followed by 40 cycles of $1 \mathrm{~min}$ at $94^{\circ} \mathrm{C}, 1 \mathrm{~min}$ at $42^{\circ} \mathrm{C}$ (ORF2) $/ 50^{\circ} \mathrm{C}(\mathrm{ORF} 1)$ and $1 \mathrm{~min}$ at $72^{\circ} \mathrm{C}$ and a final extension step of $7 \mathrm{~min}$ at $72^{\circ} \mathrm{C}$. For the second round of PCR, $3 \mu \mathrm{L}$ of DNA were added to $47 \mu \mathrm{L}$ of nested PCR mix, which was similar to the PCR mix, except that the primer sets 3158N-3159N/ORF2 and ConsORF1-s2-ConsORF1a2/ORF1 were used. A total of 30 cycles identical to those used in the first round of PCR were performed.

The amplified fragments of ORF1 (287 bp) and ORF2 (348 bp) were extracted from agarose gels using GFX ${ }^{\mathrm{TM}}$ PCR DNA and a Gel Band Purification Kit (GE Healthcare, Little Chalfont, UK) and were quantified using a Qubit $^{\mathrm{TM}}$ fluorometer (Invitrogen, Molecular Probes, Eugene, OR, USA). The fragment sequences were obtained using the DYEnamic ET Dye Terminator Kit (GE Healthcare, Pittsburgh, PA, USA) in a MegaBACE 1000/ Automated 96 Capillary DNA sequencer, using Thermo Sequenase $^{\mathrm{TM}}$ II DNA Polymerase and the DYEnamic ${ }^{\mathrm{TM}}$ ET Dye Terminator Kit (GE Healthcare, Little Chalfont, UK). A phylogenetic tree was constructed from the nucleotide (nt) sequences using the MEGA package version 4.1 with the neighbour joining method and the Kimura 2-parameter distance correction. The HEV strains identified in this study were designated as BRsw-A (GenBank IDs JN166093 and JX123025) and BRsw-B (GenBank IDs JN166094 and JX123026).

The nested RT-PCR assay targeting two different regions of the HEV genome (ORF1 and ORF2) amplified HEV RNA in two of $118(1.7 \%)$ liver samples and in one of $118(0.84 \%)$ bile samples. The ORF1 and ORF2 primer sets showed no difference in their sensitivity to HEV RNA detection. HEV genomic RNA was detected in the liver and bile of one pig and in the liver of a second pig.
The two animals were from different pig herds.

HEV sequences obtained from the bile and liver specimens of the same animal (A) shared nt identity of $100 \%$. The ORF1 and ORF2 sequences from the liver of animal B showed nt identities of $99.5 \%$ and $99.6 \%$, respectively, with the sequences from the liver and bile of animal A. The amplified ORF1 products of the HEV genome shared $82-94.2 \%$ nt identity with genotype 3 HEV strains. The ORF1 sequences showed a maximum nt identity to JYK-Sap03 (AB189931) and E21-YKH00 (AY684248) human HEV strains detected in Japan, with $94.2 \%$ and $93.4 \%$ nt identity, respectively. The sequences were also closely related ( $89.4 \%$ identity) to HEV strain $\mathrm{h} 1$, the only human autochthonous case of hepatitis E reported in Brazil (Lopes dos Santos et al. 2010). Our obtained sequences also shared $82.8-83.3 \% \mathrm{nt}$ identity with porcine strains (SW1 and SW2) previously detected by dos Santos et al. (2009) in pig herds from RJ and they shared $85.5-87.2 \%$ nt identity with strains E1, B24 and B51 from a pig slaughterhouse from the same region (dos Santos et al. 2011). The phylogenetic analyses revealed that the wild-type Brazilian porcine HEV strains from the present study clustered together with strains characterised as genotype 3 subtype $3 b$ (Fig. 1).

The swine HEV ORF2 sequences identified in this study showed nt identity between $78-89.7 \%$ with genotype 3 strains. The nt identity between these new Brazilian swine sequences and the previously described Brazilian swine HEV strains SW2, SW3, SW4 and SEBR (Paiva et al. 2007, dos Santos et al. 2009) ranged between $78.5-82.3 \%$. The topology of the phylogenetic tree obtained for the ORF2 region (Fig. 2) was similar to that generated for the ORF1 fragments. Therefore, the sequences from both regions confirmed that all of the Brazilian swine HEV isolates identified in this study clustered with genotype $3 \mathrm{~b}$ HEV strains, thereby providing validation of these results.

The nested RT-PCR assays used in the present study revealed that the presence of HEV in slaughtered pig livers and bile is not rare, as only a small number of samples from each herd was collected (10-15 samples from each herd). HEV detection is higher when pigs are between two-four months old, compared to the finishing phase of production (approximately 6 months in Brazil) and the virus is expected to be cleared in the majority of the slaughtered animals. Nevertheless, in previous study in Brazil, HEV genotype 3b was detected at a swine slaughterhouse in the Southeast Region (RJ) in 9.6\% of the bile samples; however, liver samples were not evaluated by dos Santos et al. (2011). Furthermore, different swine HEV genotypes (3c and 3f) were detected in $4.8 \%$ of serum, faecal and liver samples from slaughtered pigs in the Eastern Brazilian Amazon (de Souza et al. 2012). Therefore, the detection of HEV genome in slaughtered pigs from PR in this study confirms these previous reports and suggests that healthy pigs are potentially the main reservoirs of HEV in Brazil.

Individuals with professional contact with pigs or their environment have high rate of anti-HEV IgG seropositivity and may be at a higher risk of HEV infection than the general population (Meng et al. 2002). The con- 
sumption of offal, including smoked but uncooked pig liver and blood obtained from grocery stores, has been related to $\mathrm{HEV}$ infections in Europe, thereby indicating that HEV transmission could occur through fresh pork sausages known as figatellu (Colson et al. 2010). In the present study, HEV was found in pig livers that could be used in sausages and consumed, especially in homemade sausages that also include blood and intestinal tracts (i.e., offal that are also infected with HEV). Brazilian subjects who consume contaminated pork products, especially raw or undercooked pig liver, as well as subjects who come into close contact with infected pigs, have a potential risk of becoming infected with $\mathrm{HEV}$.

In slaughtered pigs, HEV RNA is most frequently detected in bile and faecal samples and when at least two different regions of the $\mathrm{HEV}$ genome are targeted for amplification (de Deus et al. 2007, di Bartolo et al. 2011, de Souza et al. 2012). In the present study, two different

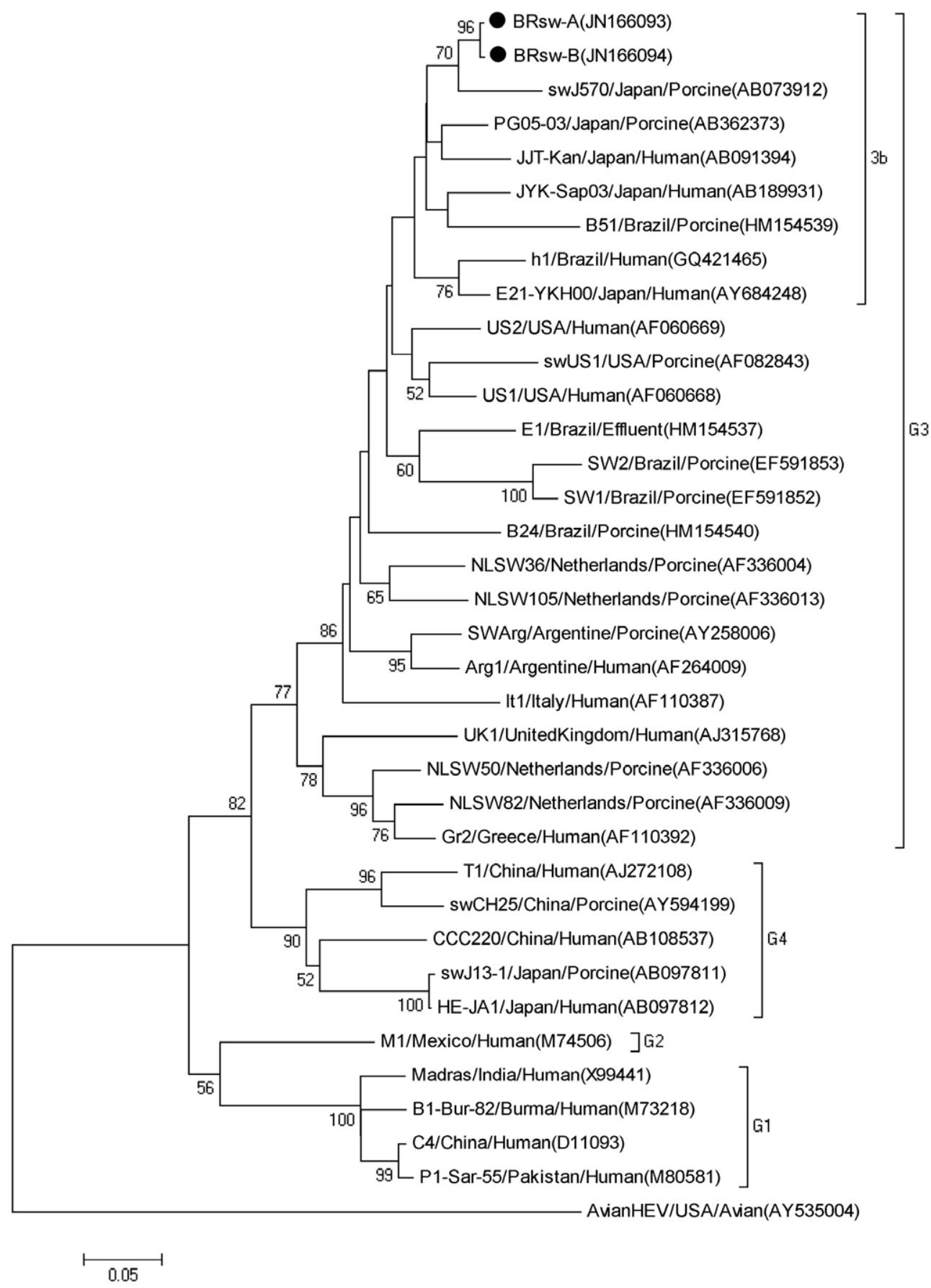

Fig. 1: phylogenetic analysis obtained using the neighbour-joining method based on the nucleotide sequences of a 228 bp region within the hepatitis $\mathrm{E}$ virus (HEV) open reading frame 1 . The bootstrap values are indicated when $>50 \%$ as a percentage was obtained from 1,000 replications. The two sequences isolated in this study are marked with circles. The scale bar represents a genetic distance of 0.05 substitutions per site. 
primer sets targeting ORF1 and ORF2 of the HEV genome were used to test bile and liver samples from all animals, although faeces and sera were not evaluated. Unlike in previous reports, HEV RNA was not most frequently detected in the bile samples. It is possible that the lower abundance $(1.7 \%)$ of HEV genotype 3 detected here compared to previously reports of slaughtered Brazilian pigs [9.6\% (dos Santos et al. 2011) and 4.8\%, (de Souza et al. 2012)] can be explained by the absence of other types of samples from the same animal used in the present study.

The results of the present study raise public health concerns in Brazil because HEV could be detected in healthy pigs under the control of the Federal Inspection
Service at the time of slaughter. These contaminated animal products are in close contact with slaughterhouse workers and the offal may be commercialised as food. The prevalence of HEV infection in humans in Brazil is unknown. However, serological studies have suggested that subclinical or undiagnosed HEV infections are possible (Carrilho et al. 2005). Additionally, the only human autochthonous case reported in Brazil (Lopes dos Santos et al. 2010) suggested a zoonotic origin of infection via the consumption of infected pork meat. The phylogenetic analysis classified this Brazilian human HEV strain as belonging to the $3 \mathrm{~b}$ genotype, which is the same genotype as the pig strains that were detected in this study.

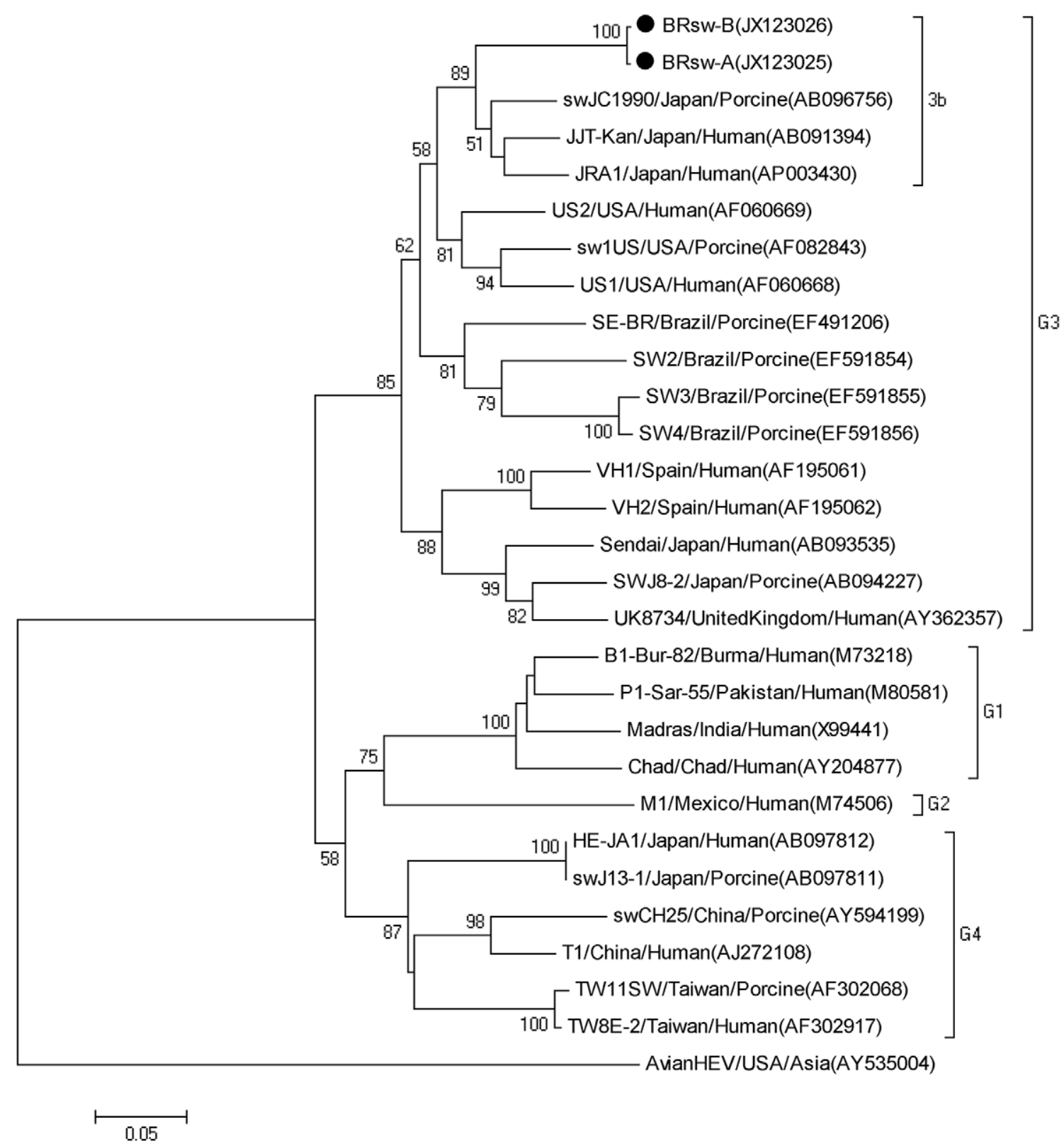

Fig. 2: phylogenetic analysis obtained using the neigh neighboor-joining method based on the nucleotide sequences of a 304 bp region within the hepatitis E virus (HEV) open reading frame 2. The bootstrap values are indicated when $>50 \%$ as a percentage was obtained from 1,000 replications. The two sequences isolated in this study are marked with circles. The scale bar represents a genetic distance of 0.05 substitutions per site. 
In conclusion, this study demonstrates that slaughterhouse workers are potentially exposed to HEV from healthy pigs in Brazil. Additionally, pig liver and offal can act as HEV vehicles to consumers that eat raw or undercooked pork products. Considering HEV circulation in Brazil and that the clinical presentation of hepatitis $\mathrm{E}$ is similar to that of other forms of acute hepatitis, HEV should be included in the differential diagnosis of patients with unexplained hepatitis. Therefore, additional studies must be performed to determine the extent to which pig liver and offal contaminated with HEV represent a public health concern, not only in PR, RJ and PA, as reported recently, but also in other regions of Brazil.

\section{REFERENCES}

Alfieri AA, Parazzi ME, Takiuchi E, Médici KC, Alfieri AF 2006. Frequency of group A rotavirus in diarrheic calves in Brazilian cattle herds, 1998-2002. Trop Anim Health Prod 38: 521-526.

Carrilho FJ, Clemente CM, da Silva LC 2005. Epidemiology of hepatitis $\mathrm{A}$ and E infection in Brazil. Gastroenterol Hepatol 28: 118-125.

Colson P, Borentain P, Queyriaux B, Kaba M, Moal V, Gallian P, Heyries L, Raoult D, Gerolami R 2010. Pig liver sausage as a source of hepatitis E virus transmission to humans. $J$ Infect Dis 202: 825-834.

Dalton HR, Bendall R, Ijaz S, Banks M 2008. Hepatitis E: an emerging infection in developed countries. Lancet Infect Dis 8: 698-709.

Dalton HR, Fellows HJ, Stableforth W, Joseph M, Thurairajah PH, Warshow U, Hazeldine S, Remnarace R, Ijaz S, Hussaini SH, Bendall RP 2007. The role of hepatitis E virus testing in druginduced liver injury. Aliment Pharmacol Ther 26: 1429-1435.

de Deus N, Seminati C, Pina S, Mateu E, Martin M, Segales J 2007. Detection of hepatitis E virus in liver, mesenteric lymph node, serum, bile and faeces of naturally infected pigs affected by different pathological conditions. Vet Microbiol 119: 105-114.

de Paula VS, Arruda ME, Vitral CL, Gaspar AMC 2001. Seroprevalence of viral hepatitis in riverine communities from the western region of the Brazilian Amazon Basin. Mem Inst Oswaldo Cruz 96: 1123-1128.

de Souza AJ, Gomes-Gouvêa MS, Soares MD, Pinho JR, Malheiros AP, Carneiro LA, dos Santos DR, Pereira WL 2012. HEV infection in swine from eastern Brazilian Amazon: evidence of coinfection by different subtypes. Comp Immunol Microbiol Infect Dis 35: 477-485.

di Bartolo J, Ponterio E, Castellini L, Ostanello F, Ruggeri FM 2011. Viral and antibody HEV prevalence in swine at slaughterhouse in Italy. Vet Microbiol 149: 330-338.

dos Santos DRL, de Paula VS, de Oliveira JM, Marchevsky RS, Pinto MA 2011. Hepatitis E virus in swine and effluent samples from slaughterhouses in Brazil. Vet Microbiol 149: 236-241. dos Santos DRL, Vitral CL, de Paula VS, Marchevsky RS, Lopes JF, Gaspar AM, Saddi TM, Júnior NCM, Guimarães FR, Júnior JG, Ximenez LL, Souto FJD, Pinto MA 2009. Serological and molecular evidence of hepatitis E virus in swine in Brazil. Vet $J$ 182: 474-480.

Emerson SU, Purcell RH 2006. Hepatitis E virus. In DM Knipe, PM Howley, DE Griffin, RA Lamb, MA Martin, B Roizman, SE Straus (eds.), Fields virology, E-Publishing, Philadelphia, p. 3047-3058.

Galiana C, Fernandez-Barredo S, Garcia A, Gomez MT, Perez-Garcia MT 2008. Occupational exposure to hepatitis E virus (HEV) in swine workers. Am J Trop Med Hyg 78: 1012-1015.

Huang FF, Haqshenas G, Guenette DK, Halbur PG, Schommer SK, Pierson FW, Toth TE, Meng XJ 2002. Detection by reverse transcription-PCR and genetic characterization of field isolates of swine hepatitis E virus from pigs in different geographic regions of the United States. J Clin Microbiol 40: 1326-1332.

Johne R, Plenge-Bonig A, Hess M, Ulrich RG, Reetz J, Schielke A 2010. Detection of a novel hepatitis E-like virus in faeces of wild rats using a nested broad-spectrum RT-PCR. J Gen Virol 91: 750-758.

Li TC, Chijiwa K, Sera N, Ishibashi T, Etoh Y, Shinohara Y, Kurata Y, Ishida M, Sakamoto S, Takeda N, Miyamura T 2005. Hepatitis E transmission from wild boar meat. Emerg Infect Dis 11: 1958-1960.

Lopes dos Santos DRL, Lewis-Ximenez LL, da Silva MFM, de Sousa PSF, Gaspar AMC, Pinto MA 2010. First report of a human autochthonous hepatitis E virus infection in Brazil. J Clin Virol 47: 276-279.

Lu L, Li C, Hagedorn CH 2006. Phylogenetic analysis of global hepatitis E virus sequences: genetic diversity, subtypes and zoonosis. Rev Med Virol 16: 5-36.

Meng XJ 2010. Recent advances in hepatitis E virus. $J$ Viral Hepat 17: $153-161$.

Meng XJ, Wiseman B, Elvinger F, Guenette DK, Toth TE, Engle RE, Emerson SU, Purcell RH 2002. Prevalence of antibodies to hepatitis $\mathrm{E}$ virus in veterinarians working with swine and in normal blood donors in the United States and other countries. J Clin Microbiol 40: 117-122.

Paiva HH, Tzaneva V, Haddad R, Yokosawa J 2007. Molecular characterization of swine hepatitis e virus from southeastern Brazil. Braz J Microbiol 38: 693-698.

Wang Y, Ling R, Erker JC, Zhang H, Li H, Desai S, Mushahwar IK, Harrison TJ 1999. A divergent genotype of hepatitis E virus in Chinese patients with acute hepatitis. J Gen Virol 80: 169-177.

Zhao C, Ma Z, Harrison TJ, Feng R, Zhang C, Qiao Z, Fan J, Ma H, Li M, Song A, Wang Y 2009. A novel genotype of hepatitis E virus prevalent among farmed rabbits in China. J Med Virol 81: 1371-1379. 